\title{
Princípio de precaução e preocupação ética: um casamento racional?*
}

\section{Principe de précaution et souci éthique: un mariage de raison?*}

\section{Precaution principle and ethical worry: a rational marriage? ${ }^{*}$}

\author{
Dominique VERMERSCH* \\ Marielle MATTHEE ${ }^{* * *}$
}

\section{Princípio de precaução e preocupação ética: um casamento racional?}

Apoiando-se no caso emblemático dos organismos geneticamente modificados (OGM), este artigo propõe um quadro sinóptico das relações imbricadas entre avanços científicos e políticas que subentendem a aplicação do princípio de precaução. A indeterminação científica que preside esta aplicação provém em parte de procedimentos de redução (de modelização), naturalmente próprios do procedimento científico, mas sempre associados de um modo ou de outro ao contexto social do momento e às representações do mundo em vigor. Incluindo em algumas delas aspectos sociais, as modelizações propostas poderão mostrar-se concorrentes e alimentar assim a controvérsia social que se desenvolve em torno das aplicações do princípio de precaução. Tal contingência é um antecedente a ser considerado no questionamento ético inevitavelmente relacionado à determinação das formas de precaução que serão adotadas.
A aplicação do princípio da precaução constitui, a partir de hoje, uma passagem obrigatória na gestão dos riscos tecnológicos e de meio ambiente. Face particularmente à amplitude das recentes catástrofes ecológicas e ao caráter ambivalente de algumas inovações, esse princípio parece, à primeira vista, um cômodo abrigo às nossas angústias coletivas. Inspiração das correntes ecológicas dos anos 80 , vítima de equívocos em suas diversas transcrições jurídicas, erigida apressadamente como dique de contenção urgente em caso de tempestade da mídia ou da sociedade e, por fim, reinterpretada ao sabor de uma pluralidade exegética, a expressão, hoje, está prestes a ser sacralizada. O princípio de precaução recobre atualmente, no âmbito da Europa, as áreas de meio ambiente, alimentação e saúde humana, fazendo lembrar a profunda imbricação existente entre elas. Essa imbricação torna-se clara no caso emblemático dos organismos transgênicos (OGM) e perpassa uma outra, mais vertical, entre ciência, tecnologia, aspectos socioeconômicos e políticos. Propõe-se a seguir um quadro sinótico, cuja

\footnotetext{
* Publicado na Revista NSS, 2001, v. 9, n. 3, p. 47-52/0 Editions.. Todos os direitos reservados. Traduçào de Maria Fernanda Araujo Lisbôa

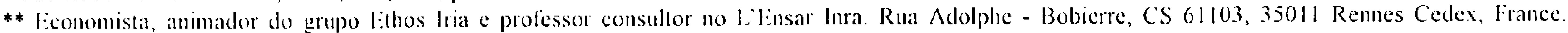
$<$ dvemerstaroakhon inra.lis

*** Jurista, Research Fellow, Asser. Institute. The llague, Pay-Bas. <m.matlledorasserni>
} 
análise permite detalhar, em um segundo momento, o questionamento ético atualmente solicitado aos interstícios do saber científico, do poder político e da responsabilidade pessoal.

\section{Na origem: a passagem do risco real à incerteza}

O esforço sem precedentes de pesquisa científica conduz a inovações tecnológicas que visam a liberar a sociedade de riscos (climáticos, alimentares e sanitários) até então recorrentes; leva também a outras inovações, cuja adoção induz eventuais riscos inéditos que podem afetar o meio ambiente e a saúde humana com efeitos de histerese; à delimitação consecutiva de "bolsões de incertezas científicas" dificilmente redutíveis.

Essa ambivalência, em parte aparente, do esforço científico e técnico é relatada nas duas primeiras colunas do quadro 1. Sustentado por uma preocupação de veracidade, esse esforço conduz freqüente e simultaneamente: à produção de conhecimentos seguros; à delimitação de novas áreas de conhecimento a explorar. $\mathrm{O}$ conjunto dá lugar a uma redução científica das realidades estudadas, isto é, a um modelo constituído das certezas supostamente adquiridas e de um espectro de hipóteses a serem verificadas, a partir das quais se espera

\section{QUADRO 1}

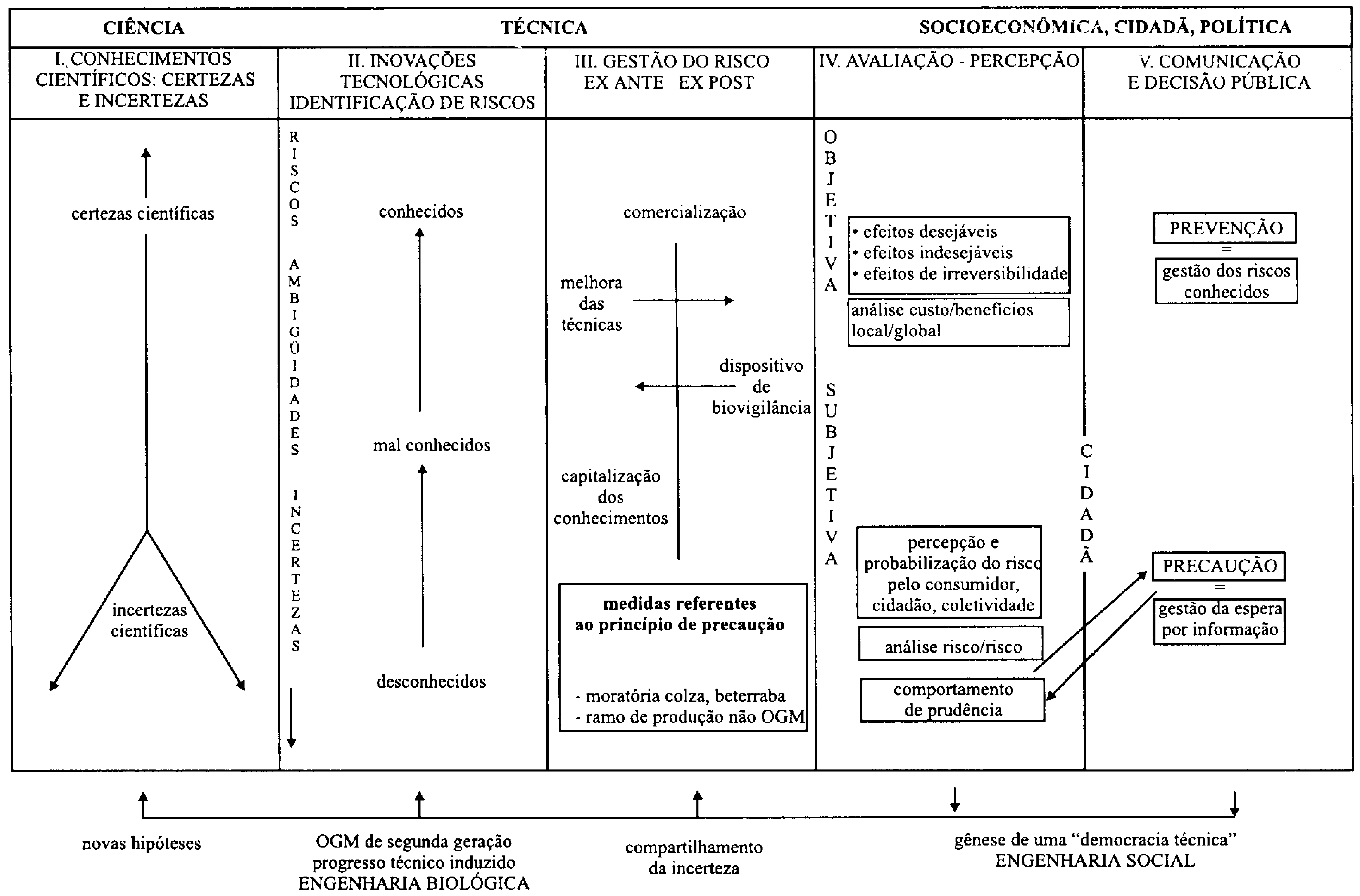


poder delimitar as novas áreas a ser exploradas. Esse modelo é evolutivo, mas estabelece, em um dado instante, a inovação tecnológica que inclui, de fato, essa parte da ambivalência citada anteriormente e relativamente determinada de acordo com o caso.

Os organismos transgênicos constituem, nesse aspecto, um caso exemplar. Como define Atlan (1999), a concomitância da descoberta da estrutura do $\Lambda \mathrm{DN}$ e do desenvolvimento da informática resultaram na elaboração de um modelo de transferência de informação genética, ele próprio importado da ciência da informática. Daí a então famosa metáfora do "programa genético", que afirma implicitamente que tudo está no genoma: caráter, identidade, reprodutibilidade dos organismos... Os primeiros desenvolvimentos da transgênese animal e vegetal fundamentaram-se no modelo básico de transferência de informação genética... hoje amplamente questionado pelos próprios avanços da genética. O genoma funcionaria mais como banco de dados do que como programa genético em interação com o conjunto do metabolismo celular. Não obstante, a inovação tecnológica que os organismos transgênicos representam, baseouse inicialmente nessa representação do genoma como programa de computador dotado de poder gerador. $\mathrm{O}$ que nos resta, como consolo, é que, se admitirmos que tudo não está no gene, o "segredo da vida" não seria, portanto, desvendado mais adiante; a retórica de Prometeu, assim como o medo de um demiurgo louco, perdem conseqüentemente sua pertinência (LARRI:RI:, 2000).

Administrar o peso da prova referente à inocuidade dos transgênicos demanda, atualmente, saber e prática científicos com vistas a um melhor conhecimento objetivo dos impactos deles no meio ambiente e na saúde. $\dot{A}$ semelhança de toda nova hipótese científica, essa última será verificada pelo viés de dados empíricos obtidos por procedimentos de redução que isolam, no campo fenomenal, as propriedades julgadas objetivas (LADRIIERL, 1997). Esse procedimento de redução é regido tanto pela realidade observada quanto pelos instrumentos analíticos validados pela prática cientifica do momento. Tratando-se, por exemplo, do fenômeno de disseminação eficaz do pólen de colza geneticamente modificado, o procedimento de redução formalizará, a partir do objeto real, um modelo biofísico retendo um certo número de parâmetros e subfenômenos quantificáveis (meteorológicos, agronômicos, cruzamentos interespecíficos...), modelo esse detentor de uma capacidade de predição do fenômeno estudado. Consequientemente, quanto mais a redução se mostrar capaz de inferir e retraçar o mais amplamente possivel o fenômeno na totalidade de sua realidade, mais parecerá pertinente.

Os procedimentos de redução utilizados na análise dos impactos ambientais dos organismos transgênicos são realizados a partir de uma escala espaço-temporal de envergadura. Trata-se, com efeito, de analisar os efeitos de modificações genômicas de espécies vegetais sobre o futuro de ecossistemas, alcançando, em alguns casos, dimensões regionais e até mesmo internacionais. Legitimar dentro da realidade das propriedades validadas por modelos agronômicos, experimentais e estatísticos, torna-se então muito complexo, dada a "escala de redução" acima citada. Um tal processo de inferência pode, além do mais, deparar-se com bolsões irredutiveis de indeterminação científica (WYNI:, 1997) tornando, dessa forma, quase impraticável uma versão radical do peso da prova exigida por alguns em nome do princípio de precaução. Da mesma maneira, compreende-se melhor, então, que em função da escala de redução em que nos situamos o gerenciamento da prova será realizado de modo muito distinto. É esse fato que explica que biologistas moleculares parecem em geral mais serenos quanto à inocuidade dos transgênicos do que seus colegas ecologistas ou agrônomos.

Quanto às vantagens comparativas, o uso agrícola dos transgênicos oferece uma redução da utilização de pesticidas e. conseqüentemente, dos riscos ambientais que the são imputados. Esse fato parece efetivo, ao menos a curto prazo. Um estudo do Iowa State University' mostrou que $13 \%$ dos farmers do Midwest que utilizam variedades de milho $\mathrm{Bt}^{2}$ reduziram as quantidades de inseticida em 1996, $19 \%$ em 1997 e $26 \%$ em 1998; além disso, a metade deles declarou sequer utilizálos. Por essa razão, preconizou-se nos Estados Unidos o hábito de se conservar zonas de milho não transgênico, a fim de reduzir o risco de aparição de pírales resistentes à toxina do gene $B t$. Contribuindo para a redução de alguns riscos ambientais, os transgênicos acarretariam outros: fluxo de genes pouco controláveis, cruzamentos

1 <http:/yankton.net/stories/112299/new $1122990012 \mathrm{html}>$

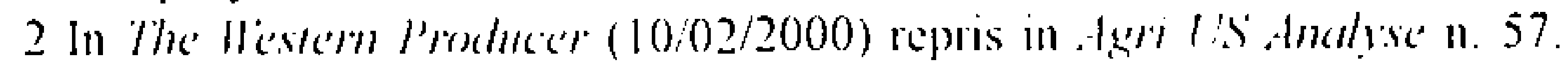


não desejáveis entre espécies vegetais, transmissão genética de resistências, efeitos sobre a entomofauna auxiliar. Entre outros acontecimentos amplamente difundidos pela mídia, testes de ADN confirmaram a tripla resistência de plantas adventícias (canola, por exemplo) que surgiram em dois anos em um campo de colza transgênica resistente de maneira específica a três herbicidas diferentes. ${ }^{2}$

O esforço científico (coluna 1) é, pois, novamente exigido e sofre inflexão para identificar os riscos (coluna 2). Alguns deles são ou serão facilmente conhecidos e mensurados, o que se traduz pela precisão adquirida da lei de probabilidade que os rege: a probabilização é então dita objetiva. De certo modo, esse é o caso da quantificação dos fluxos de genes, do modo de disseminação do pólen proveniente de OGM ou ainda da possibilidade de hibridismo interespecíficos. Mas, por um lado, sua evolução a médio prazo continua igualmente pouco conhecida. Além disso, outros riscos serão ainda menos conhecidos enquanto os métodos de identificação também estiverem sob controvérsias. Ainda estamos, portanto, no estágio de aprimoramento dos métodos de avaliação do risco alimentar dos OGM, visto que o princípio de equivalência substancialmente ora utilizado será provavelmente considerado ao longo do tempo insuficiente para os consumidores e as autoridades sanitárias. Com riscos pouco conhecidos, ou mesmo desconhecidos, a própria noção dá então lugar a outra, múltipla, da incerteza: os conhecimentos científicos do momento ainda são insuficientes e até mesmo questionados; o risco não é mais mensurado em termos probabilísticos e deixa o campo livre, a curto prazo, para uma probabilização subjetiva. Cada um de nós a realiza: consumidor, produtor, investidor, gestor público, cidadão... e ela mostra-se mais ou menos otimista ou pessimista de acordo com os interesses em jogo ou segundo o grau de rejeição ao risco pelas partes envolvidas. Este modo de probabilização subjetiva exprime na realidade a continuidade que liga as noções de risco e de incerteza; ele pode intervir enquanto o risco for real, mas dificilmente mensurável graças, por exemplo, à ínfima freqüência de um evento des- favorável. A incerteza pura corresponderia, então, a um estado da natureza teoricamente concebível, mas cuja realidade tem de ser provada. Por isso, a incerteza, na sua acepção comum, é de natureza composta. Já a probabilização subjetiva realizada pelos indivíduos seria uma expressão de sua racionalidade; a única coisa que importa é, na realidade, a credibilidade desta probabilização (SCHMIDT, 1996).

\section{Da prevenção à precaução}

Em certo aspecto, o progresso dos conhecimentos científicos contribui para reabsorver a incerteza e tornar, assim, os riscos mensuráveis, gerenciáveis e confirmáveis. A prevenção é o gerenciamento dos riscos conhecidos, gerenciamento que tem de ser realizado antecipada (ex ante) e posteriormente (ex post) à decisão geradora de impactos ambientais e sanitários potenciais. Esta é representada pela linha pontilhada ${ }^{3}$ da coluna 3 , abarcando, por exemplo, a autorização de comercialização de variedades OGM. A melhoria das técnicas de transgênese constitui medida ex ante, ao passo que a introdução de um dispositivo de biovigilância ${ }^{5}$ constitui uma medida tendendo ao ex post. A quantificação dos riscos permite também uma avaliação econômica objetiva (alto da coluna 4), integrando os diferentes efeitos positivos e negativos da inovação, os efeitos a médio e longo prazo (através de uma taxa de atualização), os efeitos irreversíveis que, sempre no caso dos OGM, podem ser de natureza ecológica (disseminação de híbridos) ou econômica (perda durável de competitividade agrícola no plano internacional...).

Por outro lado, os conhecimentos científicos do momento não podem concluir "ponto por ponto" quanto à existência ou não de um risco. Os novos esforços de pesquisa terão, então, como objetivo a passagem da incerteza a um risco que pode ser probabilizado, e transitarão freqüentemente por situações de ambigüidade: em outras palavras, situações de controvérsia científica no que se refere à medida probabilizada do risco. Evidentemente, a

3 Limha pontilhada, pois a fronteira ex ame ex post se mostra perméivel assim que essas autorizaçoes de comercialização foram escalonadas no tempo, inplieando entào uma disseminaçào dos OGM, hoje dificilmente controlável ou mesmo possivel de ser detectada (por exemplo na alimentação animal)

4 Dispositivo de vigilància biológica das culturas provenientes de vegetais provenientes de OGM colocado no mercado. $\triangle$ lei de orientaçào agricola de 9 de jullio de 1999 fixa seu quadro regulamentar. A biovigiancia visa por objetivos: a traçabilidade das semeaduras de variedades OGM, a coleta de informação sobre o comportamento dessas variedades; e sobre eventuais efeitos nào intencionais, o estudo das possibilidades teóricas de surgimento de latos desfavoráveis no meio ambiente por ocasiào do uso em grande escala das variedades OGM (CIIAT-LOCUSSOL, 1999).

5 Indeteminaçào como a autorizam ex chlte as tcorias da evoluçào. 
ambigüidade emerge proporcionalmente à extensão do campo das incertezas iniciais e do viés que caracteriza os modelos utilizados (isto é, as reduções científicas).

As controvérsias e a falta de conhecimentos científicos confirmados sobre esses riscos eventuais não invalidam a necessidade de que eles sejam prevenidos, essa é a lógica do princípio de precaução (GODARD, 1998). No plano da gestão pública, a precaução consiste concretamente em gerenciar a espera por novas informações e conhecimentos científicos, assim como comunicálos. Esse princípio leva a modos de gestão seqüiencial, flexível e reversível; à imposição de medidas justificadas de prevenção, dependentes do contexto socioeconômico; ao redirecionamento da própria natureza das informações futuras. As decisões de financiamento de pesquisas hoje condicionam a orientação e a aquisição dos novos conhecimentos científicos de amanhã (TRLICII, 1998). Esses diferentes aspectos encontramse na comunicação adotada pela Comissão Européia sobre o recurso ao princípio de precaução (Com, 2000), ou ainda no relatório KOURILSKY. VINET (1999). Eles estão exemplificados em diversas colunas do quadro 1 , que assim se dota de uma recursividade. A referência ao princípio de precaução se expressa, pois, através de:

- teste de novas hipóteses científicas (coluna 1);

- desenvolvimento de OGM ditos de segunda geração visando a minimizar os impactos ambientais potenciais (coluna 2) e isso de acordo com a lógica do progresso técnico induzido (HAYAMI; RUT"IAN, 1998);

- medidas de prevenção bastante diferentes (coluna 3): moratória de dois anos referente ao colza e à beterraba, prorrogação da suspensão de comercialização do milho transgênico da companhia Novartis pelo Conselho de Estado em dezembro de 1998...

Citemos ainda a instalação de ramos da agroindústria não relacionados ao OGM, bem como os procedimentos de etiquetagem que, espelhando-se no compartilhamento dos riscos, consentem com o compartilhamento da incerteza e das responsabilidades potenciais que poderiam ser imputadas. O conjunto dessas medidas é resultado, por outro lado, de uma apreensão política da precaução (coluna 5), ela mesma influenciada pela percepção coletiva das incertezas (coluna 4). É claro que, nesse primeiro caso, a avaliação tende realmente a reduzir-se a uma percepção subjetiva que se cristaliza em opiniões mais ou menos mediadas. A controvérsia científica, então, aumenta a controvérsia social quanto à uti- lidade da inovação, a própria perícia científica sendo colocada em dúvida no caso dos estudos de impacto dos OGM. Assim, a liberação progressiva desses últimos, tanto do ponto de vista da expertise científica que thes é associada quanto da penetração em culturas de grande escala é hoje atropelada por uma "liberação social" de proporções surpreendentes. Isso afasta, por algum tempo ainda, toda veleidade de um gerenciamento político padrão tanto em plano nacional quanto internacional (MATTIIIE; VERMLRSCH, 2000).

\section{Quando a tecnocracia se presta ì democracia técnica...}

É assim que nos deparamos, como pano de fundo, com uma questão de agora em diante recorrente: qual o modo de participação do "público" nas escolhas científicas e técnicas geradoras de incertezas? Situação paradoxal na medida em que, por um lado, uma gestão tecnocrática de interesse geral evidencia nesses casos suas limitações, "tecnicamente...". Por outro lado, essa mesma gestão tem a oportunidade de compensar sua carência democrática recuperando, sem custo, a contestação dos cidadãos a respeito dos OGM.

A conferência dos cidadãos de junho de 1998 sobre a utilização de OGM na agricultura e nos alimentos constitui uma experiência, entre outras, de "um debate público de cidadania". Apresentou-se, em poucas palavras, como uma forma inédita de "democracia técnica", colocando em discussão o espaço público de questões ligadas às orientações genéticas ou à definição de políticas industriais pró-ambientais (CALLON, 1998). Realmente, por se tratar de escolhas tecnológicas mais amplas, a questão é conjugar adequadamente o parecer científico e a democracia participativa que, aliás, estão estreitamente ligados. Algumas interpretações atuais do princípio de precaução tendem, entretanto, a vê-los como incompatíveis, pois os vislumbram sob a perspectiva de um conflito mais velado e dissimulado entre engenharia biológica e engenharia social. Com o pretexto de uma democratização certamente bem-vinda, o risco de aumentar a confusão, levando a uma espécie de mistura de gêneros, não é nulo. Uma certeza científica não pode ser deduzida de um exercício democrático, assim como o cientismo biológico e social não podem ser por si só garantia dos valores éticos que alicerçam a democracia. 
Para que sejam evitados desentendimentos e até mesmo desilusões, é conveniente desde agora delimitar exata e abertamente o campo proposto para o exercício de democracia participativa: é só uma questão de abri-lo, nessa altura, para se chegar a um acordo quanto à definição de um nível de risco aceitável (GODARD, 2000)? Ou iniciálo posteriormente, então de modo mais amplo quanto às escolhas tecnológicas e à capacidade de condicionar as evoluções da sociedade a longo prazo?

\section{A natureza pertence a todos}

Além da simples questão dos OGM, a transformação, a seleção, a manipulação do ser vivo, da natureza pelo homem, provêm sempre de um projeto social que tem evoluído muito ao longo dos tempos, ainda que seja exclusivamente do ponto de vista econômico: sobreviver, alimentar-se, comercializar, enriquecer-se, controlar os riscos... Nesse sentido, a pesquisa agronômica e suas aplicações acompanharam e têm acompanhado o projeto social. Isto posto, a inovação técnica manipuladora do ser vivo parece hoje precipitar, antecipar o projeto social, em sua composição sociológica e econômica. Não se contentando mais em acompanhar a demanda social, o poder inovador desejaria conduzi-la, ou mesmo educála: são prova disso os aspectos "pedagógicos" associados às apresentações publicitárias dos benefícios prometidos pelas biotecnologias. Sendo o engodo, às vezes, descarado, compreende-se melhor a emergência de sobressaltos coletivos, por vezes tão diferentes quanto ambíguos, contestando atabalhoadamente a privatização do ser vivo, a globalização econômica e financeira, a comida de má qualidade... Particularmente, é quando se desrespeita (política e economicamente) esta asserção popular, segundo a qual "a natureza pertence a todos", que a opinião pública sanciona, ou mesmo rejeita uma inovação privativa demais do ser vivo, que negligencia sua dimensão de bem público, dimensão por natureza dificilmente "privatizável". A rejeição à inovação é geralmente dupla: dintingue-se simultaneamente do projeto social e das representações comuns da natureza e de sua ignificação.

Parece-nos que esse duplo distanciamento remete a uma natureza que seria apreciada, ou melhor, reapreciada como uma "instância moral", isto é, uma instância capaz de esclarecer nosso próprio agir moral. De um lado, com efeito, a asserção precedente (a natureza pertence a todos) subentende que os recursos naturais e seus respectivos usos sejam eqüitativamente compartilhados. Trata-se de uma exigência feita pela própria natureza e que se deve certamente discutir, reconhecer, inclusive implementar através de diversas mediações econômicas e políticas. Deparamo-nos aqui, por exemplo, com os imperativos do desenvolvimento sustentável. Por outro lado, esta mesma natureza continua sendo incessantemente objeto de deslumbramento e de contemplação, o que nos convida a uma "economia" renovada da nature$\mathrm{za}$, isto é, a uma outra maneira de gerenciá-la, liberandoa, pelo menos em parte, dos ditames do mercado.

\section{Da indeterminação científica à convicção ética}

A natureza, instância moral - trata-se certamente de uma posição antiga como o mundo, recorrente e múltipla (BRAGUE, 1999). Levada ao extremo, ela pode cair em um empirismo radical em que a ética se reduz a uma conformidade com o dado científico originário da observação e do experimentalismo, ou seja, a uma ética positivista. Pode levar também a um ecologismo radical, no qual se pede que a ação humana se conforme às exigências estabelecidas pela própria natureza, "preocupada" que estaria com o seu futuro e com sua sobrevivência. Reconhecem-se aí as correntes ligadas à deep ecology. Tais opções refutam, finalmente, um espaço efetivo de liberdade e de responsabilidade humanas e explicam a excessiva prudência, ou mesmo a recusa extremamente significativa de reconhecer uma dimensão moral qualquer na natureza, suscetível de esclarecer a nossa ação individual e coletiva.

Isto posto, a expressão de uma racionalidade matemática inscrita na natureza é reconhecida amplamente pela comunidade científica; é por esse motivo que ainda se fala em "cosmos", termo que remete justamente à existência de uma ordem e de uma integridade próprias da natureza. A referência à inscrição de uma racionalidade na natureza é taxada, então, de finalismo, sendo até mesmo considerada marca de uma posição arcaica, irracional e perigosa. Se, evidentemente, a natureza não pode ser reduzida ao nostálgico jardim do Éden, a hipótese que desejamos reintroduzir é que ela carrega, todavia, como uma marca, a sinergia possível e efetiva entre a racionalidade científica e a racionalidade ética. Em ou- 
tros termos, entre o logos inscrito na natureza, decifrado pouco a pouco pelo esforço científico, e um agir humano racional. É nesta perspectiva que se permite aqui reler as colocações de G. Paillotin, antigo presidente do Inra: "Não quero fazer finalismo um tanto quanto simplista. Estou simplesmente constatando que há coerência nas leis da natureza e que ela não está em completa desarmonia com nossas próprias coerências sociais." (PAILLOTIN, 1997)

Retomemos, pois, a nostalgia do Éden, associada à própria natureza, ou simplesmente à imagem do jardim que evoca um lugar, um local onde gostamos de ficar. Juntemos a isso a própria etimologia do termo ética, que remete à idéia segundo a qual "ficar", "morar" num agir moral justo necessita uma "morada", um "habitat", melhor dizendo, uma comunidade de convicções partilhadas. É essa a significação do etos social como o conjunto dos costumes morais e das normas que estruturam nossas sociedades. A natureza, em parte apreendida como um jardim, como uma morada, forneceria de certa forma um esboço, uma prefiguração deste etos, prefiguração ao mesmo tempo investida na atividade agrícola e transmitida por ela. Assim apreendida, a natureza e seu devir comportariam, além disso, uma parte de indeterminação, ${ }^{7}$ definitivamente sujeita à liberdade e à criatividade humanas. Esta indeterminação inclui, por exemplo, as incertezas científicas ligadas ao uso dos OGM, indeterminação que aos poucos desaparecerá não somente pelo esforço de pesquisa científica, mas também pela preocupação ética assumida nessa área.

\section{Princípio de precaução, princípio moral?}

Será que quando a indeterminação, que rege $e x$ ante uma manipulação da natureza, puder ser resolvida por uma dupla racionalidade cientifica e ética, poder-seia formular o princípio de precaução como um princípio moral (GODARD, 2000)? Ética ou moral? Os dois termos são geralmente empregados indiferentemente e aparecem etimologicamente como sinônimos. Eles remetem à maneira de agir e viver em uma determinada comunidade humana (LADRIĖRE, 1997). Ou seja, as regras de comportamento consideradas corretas e boas, recebidas e transmitidas no interior do grupo social. Como ressalta Ladrière, a idéia de normatividade é comum aos dois termos: pendendo na sua dimensão objetiva para o termo "ética" (a norma provém de um dado cultural próprio ao grupo social); e na sua dimensão subjetiva para o termo "moral" (a norma é reconhecida interiormente, pela consciência pessoal). Ainda que o termo "ética" seja mais empregado em função provavelmente de seu caráter impessoal, relacionar uma dimensão moral ao princípio de precaução não daria justamente a idéia de uma norma de comportamento que diria respeito tanto ao agir coletivo quanto ao individual? As indeterminações científicas do momento não remeteriam ao exercício supletivo de uma liberdade humana responsável e capaz de convicção ética, de "determinação ética", se nos é permitido jogar com as palavras? É aí, então, que a consciência coletiva, hoje freqüentemente tão reduzida ao utilitarismo de um simples cálculo econômico, poderia mostrar-se como uma "co-ciência", capaz de anular sobretudo a parte angustiante da indeterminação científica e de ir além do conflito mencionado há pouco entre engenharia biológica e engenharia social. Tal possibilidade já está sendo vislumbrada, como na sugestão de Pouteau (2000), que visa a substituir o conceito de equivalência ética, fundamentado num corpus de valores éticos que permitem avaliar o conjunto do processo agroindustrial, pelo conceito de equivalência em substância, atualmente contestado na sua capacidade de avaliação do risco sanitário ligado à incorporação de componentes alimentares provenientes de variedades de OGM. 


\section{REFERÊNCIAS}

ATLAN. H. La fin du "tout génétique"? Vers de nouveaux paradigmes en biologie. Paris: Inra éditions, 1999.

BRAGUE, R. La Sagesse du monde. Ilistoire de l'expérience humaine de l'univers. Paris: Fayard, 1999.

CALLON. M. Des différentes formes de démocracie technique. Annales des Mines, p. 63-73. jan. 1998.

CHAT-LOCUSSOL. I. La biovigilance. In: INRA. SEMINAIRE DE RIESTTTUTION DES RESUITATS DE: L'AIP. 9. 1998-1999. OGM et Emirronement. [S.1.]. déc. 1999. $67 \mathrm{p}$.

\section{COMMISSION DES COMMUNAUTÉS EUROPEENNES}

- COM. Communication de la Comission sur le recours au principe de précaution. 2000.

GODARD. O (Dir). Le Principe de Précaution dans la conduite des affaires humaines. Éd de la Maison des sciences de l'homme. Paris: Inra. 1997.

GODARD. O. Le principe de précaution. Projet. n. 261. p. $51-62,2000$.

HAYAMI, Y.; RUTTAN. V. W. Agriculture et développement, une approche internationale. Paris: Inráditions. 1998.

KOURILSKY. P.: VINET, G. Le principe de précaution. Rapport au premier ministre. [S.I.]: [s.n.]. 15 octobre 1999.
LADRILRI: J. L'éthique dans l'univers de la rationalité. Namur:Artel-Fides, 1997.

L.ARRLRL: R.. Faut-il avoir peur du génic généticue'? Les Cahiers Philosophiques de Strasbourg. [S.I.]. v. 10. 200()$.

MATllll:E. M.: VIRMISSCII. D. Are the Precautionary Principle and the International Trade of (ienctically Modified Organisms Reconcilable? Jourmal of fgricultural and Einvirommental Ethics. |S.1.|. v. 12. p. 59-70. 2000).

PAILIOOTIN. G. 50 ans de recherche publique pour I'Tha. Demeter 97/98. Paris: Armand Colin. 1997.

POUTEAU. S. Beyond substantial equivalence ...ethical equivalence. Document de travail. Versailles: Inra. 2000.

SCIIMIDT. C. Risk and Uncertainty: a knightian distinction revisited. Lncertainty and Economic Thought. Schmidt Ch. Ed. Chollenham. l: lilgar. 1996.

TRI:ICH. N. Vers une théorie économique de la précaution? Revue Risques. | S.1.|. v. 32.1998.

WYNNE, 13. Controverses. indéterminations et contrôle social de la technologic. Ieçons du nucléairec et de quelques autres cas au Royaume-Uni. In: GODARD. O. (lid.). Le Principe de Précaution dans la conduite des affaires humaines. Éd de la Maison des sciences de l'homme. Paris: Inra. 1997. p. 149-178. 